\title{
PENGEMBANGAN PERANGKAT PEMBELAJARAN FISIKA BERMUATAN INTEGRASI ISLAM-SAINS UNTUK MENANAMKAN NILAI-NILAI SPRITUAL SISWA MADRASAH ALIYAH
}

\author{
Winarti \\ Prodi Pendidikan Fisika Fakultas Sains dan Teknologi \\ Universitas Islam Negeri Sunan Kalijaga \\ wina_tarazka@yahoo.co.id
}

\begin{abstract}
Abstrak
Penelitian ini bertujuan untuk mengembangkan perangkat pembelajaran fisika bermuatan Islam Sains untuk menanamkan nilai spiritual peserta didik MA. Jenis penelitian ini adalah research and development dengan model 4-D. Analisis kelayakan perangkat pembelajaran fisika dilakukan oleh ahli materi, ahli integrasi interkoneksi, ahli pembelajaran, dan guru fisika MA menggunakan skala likert. Hasil analisa data menunjukkan bahwa perangkat pembelajaran yang telah dikembangkan dinilai sangat baik dan layak untuk digunakan sebagai bahan ajar dalam pembelajaran suhu dan kalor.
\end{abstract}

Kata kunci: Perangkat Pembelajaran Fisika, Integrasi Islam-Sains, dan Nilai-Nilai Spiritual

\section{PENDAHULUAN}

Tujuan pendidikan dan pembelajaran adalah penanaman dan membentuk nilai dan watak yang baik. Undang-undang Sistem Pendidikan Nasional no 20 tahun 2003 pasal 1 mengamanatkan agar peserta didik memiliki kekuatan spritual keagamaan. Pada pasal 2 juga diamantkan bahwa pendidikan nasional beakar pada nilai-nilai agama. Gagner dan Amstrong meletakan kecerdasan spiritual dalamkecerdasan majemuk ke sembilan setelah 8 kecerdasan majemuk yang lain: linguistik, matematik logis, spasial, kinestetik, musikal, interpesonal, intrapersonal dan naturalis. Menurut kedua peneliti ini nilainilai spiritual mempunyai peran yang sangat penting dalam mencapai kesuksesan belajar.

Konsep integrasi Islam dan sains pada pembelajaran bisa menjadi solusi untuk menanamkan nilai-nilai spiritual pada siswa. Dalam konteks pembelajaran disiplin ilmu kealaman/sains, paradigma integrasiinterkoneksi dapat diaplikasikan dengan berbagai cara, termasuk dalam ilmu fisika. Paradigma integrasi di sini bukanlah berarti bahwa antar berbagai ilmu mengalami peleburan menjadi satu bentuk ilmu yang identik, melainkan terpadunya karakter, corak, dan hakikat antar ilmu tersebut dalam semua kesatuan dimensinya. Sedangkan paradigma interkoneksi adalah terkaitnya satu pengetahuan dengan pengetahuan yang lain melalui satu hubungan yang saling menghargai dan saling mempertimbangkan (Pokja UIN Suka, 2006: 26). Setelah adanya penerapan paradigma integrasi-interkoneksi dalam disiplin ilmu sains diharapkan masing-masing disiplin ilmu dapat menyadari berbagai keterbatasan yang dimiliki.

Fisika sebagai bagian dari sains dikembangkan berlandaskan pemikiran bahwa al-qur'an adalah sumber dari segala sumber ilmu pengetahuan (Agus dan Ahmad, 2006). Berlandaskan hal ini, maka pencarian kebenaran dalam bidang fisika, tidak hanya terbatas melalui kebenaran ilmiah saja, melainkan juga digali dari sumber kebenaran yang lebih lengkap atau komprehensif. Dalam hal ini antara ilmu dan agama dilihat dan difungsikan secara padu, selain bersama-sama untuk menggali kebenaran, masing-masing juga bersifat komplementer. Sebenarnya banyak sekali nilai-nilai spritual yang dapat ditanamkan dalam pembelajaran fisika karena banyak konsep dan konten fisika yang erat kaitannya dengan nilai-nilai Islam. Salah satu contohnya adalah penciptaan langit dan bumi, tatasurya, alam semesta, dan lain sebagainya yang tentu saja konsep tersebut terkait dengan nilai-nilai keislaman.

Konsep integrasi Islam dan sains pada mata pelajaran fisika belum sepenuhnya diterapkan dalam proses pembelajaran di 
JPFK, Vol. 1 No. 2, September 2015, hal 54 - 60

http://e-journal.ikippgrimadiun.ac.id/index.php/JPFK

sekolah, khususnya di sekolah-sekolah berbasis Islam. Berdasarkan hasil survey dengan melakukan wawancara dengan guru fisika dan siswa di beberapa sekolah berbasis Islam (MAN Yogyakarta I, MAN Yogyakarta III, MAN Lab UIN Yogyakarta, Madrasah Aliyah Ibnul Qayyim Putri, dan Madrasah Aliyah Nurul Ummah) menyatakan bahwa selama ini penanaman nilai Islam tidak terintegrasi dengan pembelajaran khususnya pembelajaran Fisika. Penyampaian materi fisika belum ada yang dikaitkan dengan ayat Al-qur'an. Hal ini dikarenakan tidak tersedianya sumber belajar yang mengintegrasikan Islam dan Sains.

Sebagai salah satu upaya memperoleh capaian dari fungsi pendidikan sebagaimana disebutkan dalam UU Sistem Pendidikan Nasioanl di atas, penanaman nilai-nilai keagamaan melalui proses integrasiinterkoneksi konten Al-Qur'an dalam berbagai disiplin keilmuan merupakan opsi yang dapat ditawarkan, termasuk dalam disiplin ilmu sains. Dengan penanaman nilai-nilai keagamaan tersebut diharapkan siswa tidak hanya berpikir apa yang ada dan apa yang terjadi, melainkan juga dapat merenungkan dan memahami bahwa ada sesuatu yang Maha Besar di balik peristiwa kealaman atau fisis yang menjadi objek dalam ilmu sains. Hal ini sesuai dengan hasil penelitian yang dilakukan Yati Komalasari pada (2009) menyatakan bahwa RPP, LKS, dan Modul integrasiinterkoneksi dengan paradigma islam dapat merangsang peserta didik untu berperan aktif dan kooperatif di dalam kelas, serta dapat memahami materi fisika secara menyeluruh.

\section{METODE}

Penelitian ini merupakan Educationel Research and Development ( $\mathrm{R}$ dan $\mathrm{D})$. Educational Research and Development adalah suatu proses yang digunakan untuk mengembangkan dan memvalidasi produk pendidikan (Borg dan Gall, 1983:772). Prosedur dalam penelitian ini menggunakan model 3-D yang diadaptasi dari pengembangan perangkat model 4-D (four $D$ model) seperti yang dikemukakan oleh Sivasailam Thiagarajan, Dorothy S. Semmel, dan Melvyn I. Semmel (1974). Model ini terdiri dari 4 tahap pengembangan, yaitu Define, Design, Develop, and Disseminate, Thiagarajan, Semmel, \& Semmel (1974: 5).
Tahap Pendefinisian (Define) yang meliputi analisis kebutuhan, analisis materi, penentuan sumber belajar. Analisis kebutuhan bertujuan untuk memunculkan dan menetapkan masalah dasar yang dihadapi dalam pembelajaran. Analisis materi dan penentuan sumber belajar bertujuan untuk merangkum hasil dari analisis konsep untuk menentukan kemampuan dasar dari objek penelitian.

Tahap yang kedua adalah Tahap Perancangan (Design) yang meliputi pemilihan format, studi literatur materi, desain awal modul dan produk. Pemilihan format media bertujuan untuk mengidentifikasi media pembelajaran yang relevan dan menentukan format dalam mendesain produk yang akan dikembangkan. Pada penelitian ini yang dikembangkan adalah perangkat pembelajaran bermuatan integrasi Islam-sains untuk menanamkan nilai-nilai spiritual pada siswa. Studi literatur materi digunakan untuk memperoleh sumber yang akurat mengenai materi yang akan disajikan dalam modul pembejaran. Selanjutnya pembuatan produk yang berupa silabus, RPP, modul pembelajaran, dan bahan evaluasi.

Tahap selanjutnya Tahap Pengembangan (Develop) meliputi validasi dan revisi, uji coba lapangan skala kecil dan revisi produk, uji coba lapangan skala besar dan produk akhir. Pada penelitian ini tahap validasi dilakukan oleh para ahli yang terdiri dari dosen pendidikan fisika,dan dosen ahli integrasi Islam-sains. Setelah proses validasi dilanjutkan dengan penilaian produk. Penilaian produk merupakan tahap penilaian yang dilakukan oleh tim ahli. Penilaian dilakukan oleh ahli materi, ahli integrasi Islam-sains, dan guru madrasah. Hasil penilaian dari tim ahli akan dijadikan pedoman sebagai perbaikan produk yang dikembangkan.

Instrumen yang digunakan dalam penelitian ini berupa angket/kuisioner. Instrumen kuisioner sebagai lembar penilaian kualitas produk digunakan untuk mendapatkan data tentang kelayakan fisika hasil pengembangan mulai dari aspek konsep, aspek kelayakan isi, struktur kebahasaan, teknis penggunaan, dan desain. 
Analisis kelayakan perangkat pembelajaran fisika dilakukan oleh ahli materi, ahli integrasi interkoneksi, ahli pembelajaran, dan guru fisika MA. Adapun langkah-langkah yang dilakukan yaitu, langkah pertama, pengubahan hasil penilaian dari ahli materi, ahli media dan guru fisika MA yang masih dalam bentuk huruf diubah menjadi skor sesuai dengan skala likert (Eko Putro Widoyoko, 2012: 116).
Langkah kedua, menghitung skor rata-rata dari setiap aspek yang dinilai dengan cara menghitung jumlah skor jawaban seluruh penilai dibagi dengan jumlah penilai dikali jumlah butir jawaban. Langkah ketiga, ratarata skor penilaian aplikasi perangkat pembelajaran fisika tersebut diubah menjadi nilai kualitatif berdasarkan tabel kriteria penilaian. Penelitian ini menggunakan skala 4 maka tabel kriteria kualitatif ditunjukkan seperti Tabel 1 berikut.

Tabel 1. Kriteria Penilaian Produk

\begin{tabular}{ll}
\hline \multicolumn{1}{c}{ Rerata skor } & \multicolumn{1}{c}{ Kriteria kualitatif } \\
\hline $3,25<\mathrm{X} \leq 4,00$ & Sangat Baik (SB) \\
\hline $2,50<\mathrm{X} \leq 3,25$ & Baik (B) \\
\hline $1,75<\mathrm{X} \leq 2,50$ & Kurang (K) \\
\hline $1,00<\mathrm{X} \leq 1,75$ & Sangat Kurang (SK) \\
\hline \multicolumn{2}{c}{ Sumber: Eko Putro Widoyoko,2012: 112}
\end{tabular}

\section{HASIL DAN PEMBAHASAN}

Penelitian ini mengembangkan produk berupa perangkat pembelajaran fisika bermuatan integrasi Islam-sains untuk menanamkan nilai-nilai spiritual siswa madrasah aliyah. Adapaun macam perangkat yang dikembangkan adalah silabus, RPP, modul pembelajaran, dan soal evaluasi. Seluruh perangkat pembelajaran sudah divalidasi oleh para ahli yang terdiri dari ahli pendidikan fisika, ahli fisika dan ahli integrasi Islam-sains. Sedangkan untuk validasi instrumen yang digunakan untuk memperoleh data dilakukan oleh seorang ahli evaluasi.

Sebelum mengembangkan perangkat pembelajaran ini peneliti melakukan focus group discusion (FGD) untuk mengidentifikasi kebutuhan-kebutuhan apa saja yang harus dipenuhi dalam perangkat sehingga perangkat yang dikembangkan ini dapat membantu dalam membelajarkan fisika di Madrasah Aliyah. Hal ini senada dengan pernyataan yang disampaikan Rustiyanti (2009) yaitu bahwa penyusunan modul dan termasuk bahan ajar harus memiliki kriteria dapat dilaksanakan di sekolah. Oleh karena itu penyusunannya harus disesuaikan dengan kebutuhan siswa dan guru yang ada di sekolah. Jika hal tersebut tidak terpenuhi, maka bahan ajar dan modul tidak akan bisa digunakan siswa dan guru sebagai pedoman dalam pelaksanaan pembelajaran. Hasil dari FGD tersebut menjadi acuan untuk mengembangkan draft awal yang menjadi embrio dari perangkat yang dikembangkan.

\section{a. Penilaian Modul}

Penilaian produk berupa modul fisika bermuatan integrasi Islam-sains untuk menanamkan nilai-nilai spiritual siswa madrasah aliyah dilakukan oleh ahli materi, ahli media, ahli integrasi Islamsains, dan guru fisika Madrasah Aliyah. Tujuan dari penilaian produk ini adalah untuk mengetahui kualitas perangkat pembelajaran yang telah dibuat. Selain itu, penilaian produk juga bertujuan untuk mendapatkan kritik dan saran terhadap perangkat pembelajaran yang telah dibuat. Data hasil penilaian perangkat pembelajaran yang telah dinilai oleh ahli materi, ahli media dan ahli Islam-sains adalah sebagai berikut.

Tabel 2. Data Penilaian ahli materi

\begin{tabular}{|c|c|c|c|c|c|c|c|c|}
\hline \multirow{3}{*}{ Aspek Penilaian } & \multirow{3}{*}{$\begin{array}{l}\text { Kriteria } \\
\text { Penilaian }\end{array}$} & \multirow{2}{*}{\multicolumn{3}{|c|}{ Penilai }} & \multirow{3}{*}{ Skor } & \multirow{3}{*}{$\begin{array}{c}\text { Skor } \\
\text { per } \\
\text { Aspek }\end{array}$} & \multirow{3}{*}{$\begin{array}{l}\text { Rata- } \\
\text { Rata }\end{array}$} & \multirow{3}{*}{ Kategori } \\
\hline & & & & & & & & \\
\hline & & 1 & 2 & 3 & & & & \\
\hline \multirow[t]{2}{*}{ Aspek Peulisan } & 1 & 4 & 3 & 4 & 11 & \multirow[t]{2}{*}{21} & \multirow[t]{2}{*}{3,5} & Sangat \\
\hline & 2 & 4 & 3 & 3 & 10 & & & Baik \\
\hline \multirow{2}{*}{$\begin{array}{l}\text { Kebenaran } \\
\text { Konsep }\end{array}$} & 3 & 4 & 3 & 4 & 11 & \multirow[t]{2}{*}{11} & \multirow[t]{2}{*}{3,67} & Sangat \\
\hline & & & & & & & & Baik \\
\hline \multirow{2}{*}{$\begin{array}{l}\text { Kedalaman } \\
\text { Konsep }\end{array}$} & 4 & 4 & 4 & 4 & 12 & \multirow[t]{2}{*}{23} & \multirow[t]{2}{*}{3,8} & Sangat \\
\hline & 5 & 4 & 3 & 4 & 11 & & & Baik \\
\hline Keluasan Konsep & 6 & 3 & 3 & 4 & 10 & 19 & 3,16 & Baik \\
\hline
\end{tabular}


JPFK, Vol. 1 No. 2, September 2015, hal 54 - 60

http://e-journal.ikippgrimadiun.ac.id/index.php/JPFK

\begin{tabular}{|c|c|c|c|c|c|c|c|c|}
\hline & 7 & 3 & 4 & 2 & 9 & & & \\
\hline \multirow[b]{3}{*}{ Kebahasaan } & 8 & 3 & 3 & 4 & 10 & \multirow[t]{3}{*}{31} & \multirow[t]{3}{*}{3,5} & Sangat \\
\hline & 9 & 4 & 3 & 4 & 11 & & & Baik \\
\hline & 10 & 3 & 3 & 4 & 10 & & & \\
\hline Jumlah Skor & & 36 & 32 & 37 & 105 & 105 & 3,5 & $\begin{array}{l}\text { Sangat } \\
\text { Baik }\end{array}$ \\
\hline
\end{tabular}

Berdasarkan tabel 2 setiap aspek penilaian mendapatkan skor yang berbedabeda dan sebagian besar dikategorikan sangat baik. Pada aspek penulisan, kedalaman konsep dan kebenaran konsep berada pada kategori sangat baik erhadap ketiga penilai. Pada aspek keluasan konsep diperoleh skor rata-rata sebesar 3,5 dan berada pada kategori Baik.

Tabel 3. Data Penilaian ahli Integrasi- Interkoneksi

\begin{tabular}{|c|c|c|c|c|c|c|c|}
\hline \multirow{2}{*}{ Aspek Penilaian } & \multirow{2}{*}{$\begin{array}{c}\text { Kriteria } \\
\text { Penilaian }\end{array}$} & \multicolumn{2}{|c|}{ Penilai } & \multirow{2}{*}{$\begin{array}{l}\text { Total } \\
\text { Skor }\end{array}$} & \multirow{2}{*}{$\begin{array}{c}\text { Jumlah } \\
\text { Per Aspek }\end{array}$} & \multirow[t]{2}{*}{ Rata-Rata } & \multirow[t]{2}{*}{ Kategori } \\
\hline & & 1 & 2 & & & & \\
\hline \multirow{2}{*}{$\begin{array}{l}\text { Integrasi } \\
\text { Interkoneksi }\end{array}$} & 1 & 3 & 4 & 7 & \multirow[t]{2}{*}{11} & \multirow[t]{2}{*}{2,75} & \multirow[t]{2}{*}{ Baik } \\
\hline & 2 & 1 & 3 & 4 & & & \\
\hline \multirow{2}{*}{$\begin{array}{l}\text { Penanaman Nilai- } \\
\text { nilai Keislaman }\end{array}$} & 3 & 3 & 3 & 6 & \multirow[t]{2}{*}{14} & \multirow[t]{2}{*}{3,5} & \multirow[t]{2}{*}{ Sangat Baik } \\
\hline & 4 & 4 & 4 & 8 & & & \\
\hline Kemanfaatan & 5 & 3 & 4 & 7 & \multirow[t]{2}{*}{14} & \multirow[t]{2}{*}{3,25} & \multirow[t]{2}{*}{ Sangat Baik } \\
\hline $\begin{array}{l}\text { Integrasi } \quad \text { Islam } \\
\text { Sain }\end{array}$ & 6 & 3 & 4 & 7 & & & \\
\hline Jumlah Skor & & 17 & 22 & 39 & 39 & 3,25 & Baik \\
\hline
\end{tabular}

Berdasarkan tabel 2 setiap aspek mendapatkan skor yang berbeda-beda, aspek penilaian penanaman nilai-nilai keislaman dan manfaat integrasi islam sains memiliki skor 3,5 dengan kategori sangat baik. Sedangkan aspek penilaian integrasi islam-sains mendapatkan rata-rata yang paling rendah yaitu 2,75 .

Penilaian produk perangkat pembelajaran fisika bermuatan integrasi Islam-sains untuk menanamkan nilai-nilai spiritual siswa madrasah aliyah melibatkan beberapa orang ahli materi. Ahli materi yang dimaksud adalah orang yang ahli di bidang pendidikan fisikHal ini dimaksudkan untuk menilai apakah konsep fisika yang ada di modul fisika kalor yang terintegrasi islam-sains sudah benar atau tidak terjadi miskonsepsi.
Aspek ini berbeda dengan beberapa aspek lainnya karena menurut saran para ahli materi modul yang dikembangkan masih banyak yang merupakan pada hal-hal baru yang ada dalam kejadian sehari-hari dan masih sedikit sekali informasi terbaru yang terkait terhadap kalor yang disajikan dalam modul ini. 
Pemberian kalor pada suatu zat tidak selalu menyebabkan suhunya naik. Pada es yang sedang melebur, suhunya tetap $0^{\circ} \mathrm{C}$ walaupun diberi kalor terus sampai semua es berubah menjadi air. Sama halnya dengan air yang sedang mendidih, suhunya tetap $100^{\circ} \mathrm{C}$ walaupun diberi kalor terus sampai semua air benubah menjadi uap. Dalam Al-Quran Allah telah memberikan informasi kepada manusia tentang proses perubahan wujud zat yang tertuang dalam surat ALKahfi ayat 96 :

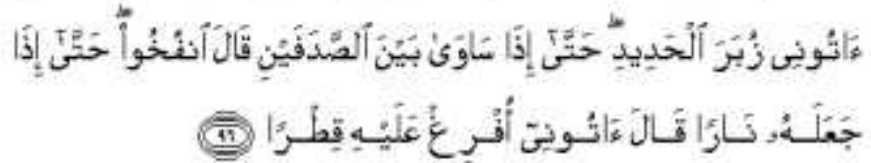

"Berilah aku potongan-potongan besi", hingga apabila besi itu telah sama rata dengan kedua (puncak) gumung itu, berkatalah Dzulkarnain: "Tiuplah fapi ine". hingga apabila besi itu sudah menjadi (merah seperti) api, diapan berkata: "Berilah aku tembaga (jang mendidih) agar aka kutuangkan ke atas besi panas inu"

Gambar 1. Contoh materi kalor terintegrasi islam sains yang terdapat di modul

Selain materi yang terintegrasi dengan Islam ( ayat-ayat Al Quran) modul juga dilengkapi dengan refleksi. Refleksi ini bertujuan untuk memberi renungan kepada siswa tentang kebesaran Allah untuk menanamkan nilai nilai keislaman pada siswa

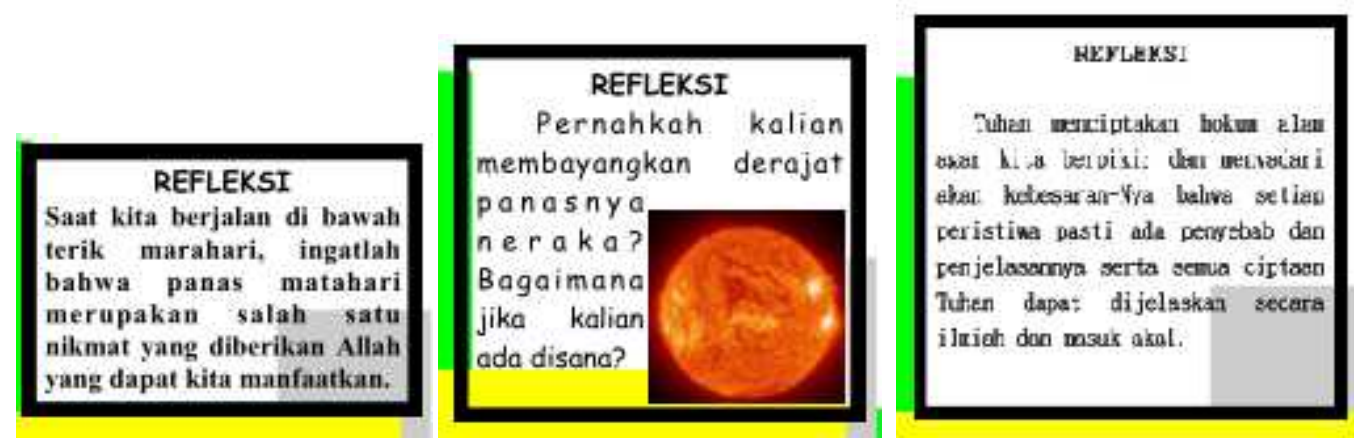

Gambar 2. Contoh Refleksi yang ada pada Modul

Kelebihan lain dari modul yang dikembangkan dalam penelitian ini adalah disajikannya eksperimen fisika yang dapat di kembangkan guru sebagai bahan pembelajaran dan kegiatan praktikum dalam pembelajaran. Pada modul ini eksperimen yang dikembangkan tidak seperti eksperimen biasanya karena langkah-langkah eksperimen tidak disajikan dalam prosedur. Hal ini dilakukan agar siswa mampu mengembangkan kemampuan berpikir kreatif dalam menentukan langkah eksperiman apa yang sesuai dengan alat dan bahan yang disediakan untuk mencapai tujuan dari eksperimen ini. 
JPFK, Vol. 1 No. 2, September 2015, hal 54 - 60

http://e-journal.ikippgrimadiun.ac.id/index.php/JPFK

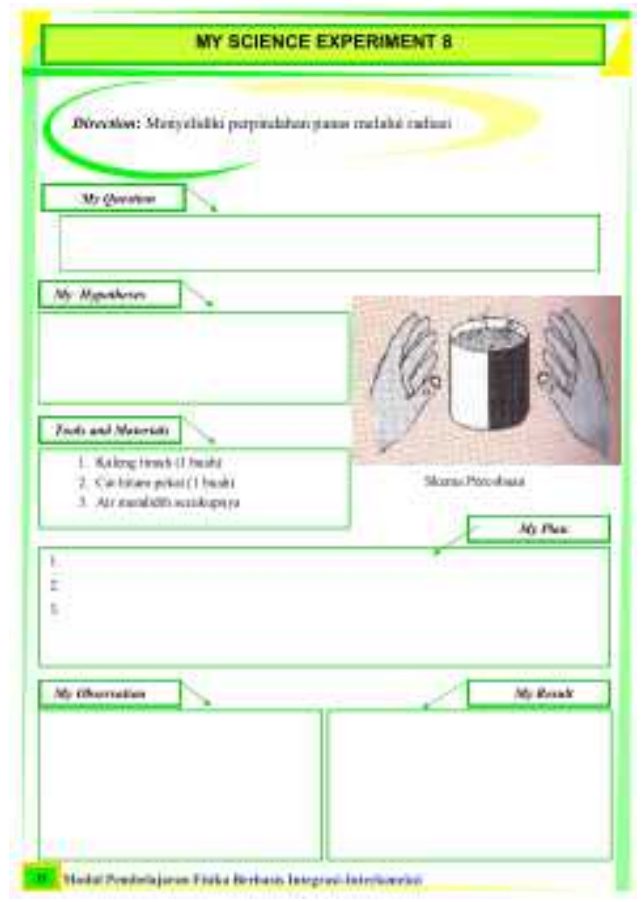

Gambar 4. Contoh eksperimen yang disajikan pada modul.

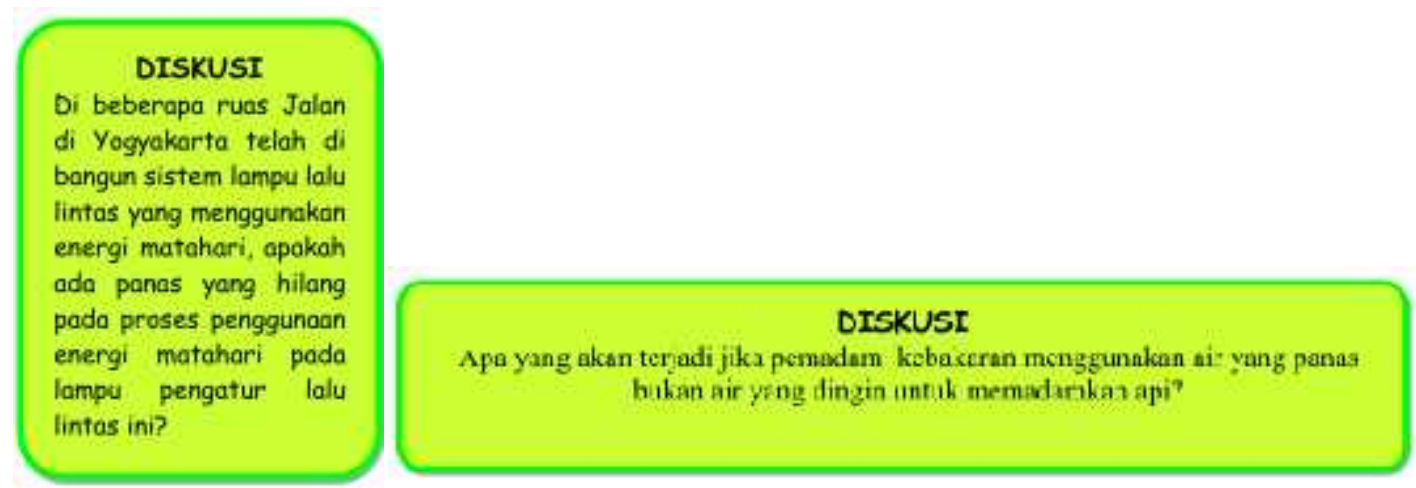

Gambar 5. Diskusi yang disajikan dalam modul

Diskusi yang disajikan dalam modul ini merupakan bagian yang penting agar siswa mampu menganalisis fenomena baru dan mengasah kemampuan analisis siswa. Dengan adanya diskusi ini diharapkan dapat memperluas wawasan siswa terkait fenomenafenomena fisika khususnya suhu dan kalor tetapi dalam yang membutuhkan kemampuan berpikir pada level yang tidak biasa.

Secara umum penilaian ahli materi, ahli media, dan guru menyatakan modul ini sangat baik dengan segala kelebihannya dibandingkan dengan modul-modul ataupun buku fisika yang telah ada dan digunakan.

Untuk Perangkat lain berupa RPP dan Silabus ahli materi dan guru menilai positif dan baik. Selain memberikan penilaian baik terhadap produk yang telah dikembangkan, ahli materi juga memberikan kritik dan saran terhadap produk. Adapun kritik dan saran tersebut yaitu untuk memperbanyak materi dalam modul dan RPP, soal evaluasi sebaiknya diperbanyak, untuk kegiatan my experience pada modul itu perlu dikembangkan praktikum baru untuk memperluas wawasan guru dan siswa.

Ketika konsep fisika dikaitkan dengan ayat Al-Quran dalam pembelajaran, siswa merasa tertarik karena mendapatkan hal-hal baru yang sebelumnya belum pernah didapatkan. Berdasarkan Uji lapangan didapatkan bahwa siswa sangat antusias mengikuti pembelajaran dan menjadi lebih ingin tau lagi tentang konsep-konsep fisika lain yang dapat dikaitkan dengan ayat-ayat $\mathrm{Al}$ 
JPFK, Vol. 1 No. 2, September 2015, hal 54 - 60

http://e-journal.ikippgrimadiun.ac.id/index.php/JPFK

Qur'an. Hal ini sesuai dengan pendapat yang dikemukakan guru saat wawancara bahwa siswa akan sangat tertarik apabila ada sentuhan ayat dan nilai-nilai keislaman dalam pembelajaran fisika.

\section{KESIMPULAN}

Kesimpulan yang dapat diambil dalam penelitian ini diantaranya: 1) pengembangan perangkat pembelajaran bermuatan integrasi Islam-sains untuk menanamkan nilai-nilai spiritual telah dikembangkan melalui prosedur penelitian pengembangan $4 \mathrm{D}, 2$ ) kualitas perangkat pembelajaran pada materi kalor secara keseluruhan berdasarkan penilaian ahli materi, ahli integrasi Islam sains, dan guru madrasah memiliki kualitas sangat baik, sehingga dapat disimpulkan perangkat pembelajaran yang telah dikembangkan layak untuk digunakan.

\section{DAFTAR PUSTAKA}

Agus Mulyono dan Ahmad Abtokhi. (2006). Fisika dan Al-Qur'an. Malang : UIN Malang Press.

Amin Abdullah. (2010). Islamic Studies di Perguruan Tinggi: Pendekatan Integratif-Interkonektif. Yogyakarta : Pustaka Pelajar.

Borg, W.R. \& Gall, M.D. (1983). Educational research: an introduction. $4^{\text {th }}$ Edition. New York: Longman Inc.

Cecep Kustadi dan Bambang Sutjipto. (2013). Media Pembelajaran; Manual dan Digital Edisi Kedua. Bogor : Ghalia Indonesia.
Eko Putro Widoyoko. (2012). Teknik Penyusunan Instrumen Penelitian. Yogyakarta: Pustaka Pelajar

F. Yuliawati, Rokhimawan, J. Suprihatiningrum.

(2013). Pengembangan Modul Pembelajaran Sains Berbasis Integrasi Islam-Sains untuk Peserta Didik Difabel Netra MI/SD Kelas 5 Semester 2 Materi Pokok Bumi dan Alam Semesta. Jurnal Pendidikan IPA Indonesia, 2 (2): 169177.

Gwynm, J.N. (1961). Theory and Practice of Supervision. New York; Wn.C Brown Company

Harun Yahya. (2007). Al-Qur'an dan Sains. Bandung : PT. Syaamil Cipta Media.

Pokja Akademik. (2006). Kerangka Dasar Keilmuan dan Pengembangan Kurikulum Universitas Islam Negeri (UIN) Sunan Kalijaga Yogyakarta. Yogyakarta : Pokja Akademik UIN Sunan Kalijaga.

Ratna Wilis Dahar. (2011). Teori-Teori Belajar \& Pembelajaran. Jakarta : Erlangga.

Rustiyanti. (2009). Implementasi Pembelajaran Modular di SMPN 1 Lamongan. Surabaya: Unnesa

Sears dan Zemansky. (2002). Fisika Universitas Jilid 1 Young Freedman. Jakarta: Erlangga

Thiagarajan, Sivasailam and others. (1972). Instructional Development for Training Teachers of Exceptional Children: A Sourcebook. Virginia: Association Drive, Reston. 